\title{
RESTORATIVE JUSTICE PRACTICES: MAKING SCHOOLS SAFE THROUGH RELATIONSHIP
}

\author{
Samuel Song, Taylor Milner, Tara Raines \\ Heather Thompson, Alexis Sliva
}

\begin{abstract}
Restorative justice practices (RJP) are strategies and interventions that apply the restorative philosophy of relationships, empowerment, and collaboration to schools. Restorative justice practices have been shown to be effective across a range of important school outcomes including growth in academics, school safety, and relationships within schools (teachers, students, families). The benefits associated with RJP are causing them to become an increasingly popular approach to discipline issues in schools in the U.S and internationally. However, in order to maximize the potential long-term benefits associated with RJP, it is essential they be consistently implemented across all schools at a national level, which will require adjustments to existing educational legislation.
\end{abstract}

\section{Keywords}

restorative justice practice, elementary schools, collaboration and relationships in schools, school culture, school climate

\section{Policy Recommendations}

The following policies are written from a U.S. perspective, as the authors are in the U.S. It is anticipated that these policies may still be useful to an international audience.

Exclusionary discipline should be eliminated for children pre-K thru 5 th grade. For all other students, it should be reduced and used only as a last option. Policy should be developed to implement a phased, cessation on zero tolerance policies (and automatic suspension and expulsion) beginning with elementary schools. Data on exclusionary discipline (suspensions and expulsions) by race and disability status should be made available to the public. 
Permanent exclusionary discipline should be used only when necessary and after other interventions and supports have been implemented. Only children who have gone through a disciplinary process that incorporates due process safeguards, have been identified as repeat offenders, have been referred to mental health professionals and received adequate support, and are still deemed by administrators and health professionals to pose a safety concern to themselves and others, should be excluded from comprehensive schools.

An indicator that recognizes schools for an overall reduction in exclusionary discipline including a reduction in disproportionality should be introduced in cities or districts such as the Common School Performance Framework [CSPF] (Yatsko, 2014). As part of this initiative, require public access to discipline data by school, sub-group, and offense in compliance with existing law.

Fund comprehensive restorative practice models to improve school culture, climate, safety, and student outcomes. Restorative practices should be implemented in a comprehensive manner throughout the school across multiple tiers (MTSS).

\section{Restorative Justice Practices: Making Schools Safe Through Relationships}

The Columbine tragedy of 1999 and other school tragedies over the past twenty years have highlighted several facts about school safety. First, milder forms of school violence such as bullying and hostile school climate are linked to extreme violence in schools (Leary, Kowalski, Smith \& Phillips, 2003). These milder forms of violence are best addressed through comprehensive approaches that focus on prevention. Second, "get tough" approaches like increased security measures, armed guards, and zero tolerance policies including exclusionary discipline are ineffective. These approaches also have disproportionate or unequal outcomes for students based on race and disability. These differences in outcomes ironically make schools less safe for many students. While some security measures like single entrance to schools may be helpful, they are only part of the equation in creating safe schools.

Third, effective school safety strategies must include comprehensive prevention and intervention programming for positive behavior and discipline. Positive behavior and discipline programs are in no way aimed at "letting students off the hook" or allowing them to "get away" with bad behavior. These programs, instead, offer the opportunity for students to learn what is expected of them and make repair for their transgressions in the school community. One effective method for approaching student behavior from a positive, preventative perspective is the implementation of Restorative justice practices (RJP). Restorative justice practices in schools have been gaining popularity as an alternative to punitive and/or exclusionary discipline. Restorative justice practices foster overall positive behavior and discipline that makes schools safer for all students. The purpose of this paper is to highlight the benefits and challenges of RJP and provide tips for successful RJP. We conclude this paper with recommendations and considerations for developing policy to support optimal implementation of RJ practices in schools. 


\section{What are Restorative Justice Practices?}

Restorative Justice practices (RJP) are strategies and interventions that apply the restorative justice (RJ) philosophy to schools. This philosophy includes promoting a culture that focuses on relationships, empowerment, and collaboration (Song \& Swearer, 2016). Students who violate school rules, those who are impacted by rule violations, and community members (e.g., administrator, facilitator, bystander) meet together to share how the violation harmed the relationships within the community and determine collaboratively how the students who caused the harm can take responsibility for it and make repair. There are a variety of ways to achieve these goals in schools: proactively building relationships, empowering the school community, and promoting collaboration among school personnel, students, and families. This approach leads to prevention of harms and the enhancement of school safety. These strategies are also well suited to be used in response to behavioral infractions and help schools intervene effectively and prevent further harms from occurring. These strategies collectively in schools are referred to as restorative justice practices (RJP).

\section{Effectiveness of Restorative Justice Practices}

Restorative justice practices (RJP) are an effective alternative to exclusionary discipline systems such as zero tolerance policies. The reason for this is that RJP have been shown to be effective across a range of important school outcomes that matter for high school graduation. These findings have been replicated in schools and districts around the country and internationally (Gregory, Huang, Anyon \& Greer, 2018; High Hopes Campaign, 2012; Kehoe, Bourke-Taylor \& Broderick, 2018; Lewis, 2009; Mansfield, Fowler \& Raibolt, 2018; McCluskey, Lloyd, Kane, Stead, Riddell \& Weedon, 2008; Russell \& Crocker, 2016; Sumner, Silverman \& Frampton, 2010; Wong, Cheng, Ngan \& Ma, 2011). Importantly, these findings have been replicated in randomized controlled trials (RCTs), which is the gold standard for demonstrating efficacy (Augustine et al, 2018). Also, it is important to highlight that the research in RJ in non-school settings shows strong evidence for effectiveness across thirty years.

Exclusionary discipline. The most commonly studied outcomes of RJP are rates of exclusionary discipline and their disproportionality across race and disability. Current research findings suggest that the evidence base for the effectiveness of restorative practices in school settings is greatest for student suspensions and behavioural referrals (Weeber \& Vereenooghe, 2020). Restorative justice practices has produced significant reductions in suspensions ranging from $40 \%$ to $90 \%$ (within the same year of implementation in some cases), a decrease in repeat offending, significantly fewer discipline referrals (decrease up to $80 \%$ ), and reductions in the disproportionality of exclusionary discipline for African Americans at the class and school levels.

School culture and climate. Another commonly studied outcome of RJP is school culture and climate, which is an important factor to enhance school safety. Schools implementing 
RJP have enhanced school climate and improved school culture (Mansfield, Fowler \& Raibolt, 2018). When students are asked about their thoughts and feelings regarding the use of restorative approaches, they tend to report benefits including increased self esteem and social and emotional skills (Gregory, Huang, Anyon \& Greer, 2018; Russell \& Crocker, 2016). Students who have reported experiencing restorative practices also indicate a more positive perspective on school climate, school connectedness, peer attachment, social skills and lower frequency of bullying; particularly physical and cyberbullying (Katic et al., 2020). Teaching and increasing the use of social-emotional skills has been shown to "reduce student behaviour problems such as aggression, and bullying as well as rates of anxiety and depression" (Kehoe, Bourke-Taylor \& Broderick, 2018). Additionally, teacher-student relationships improved when RJP was used more.

Academics and school performance. There are a number of important findings on academics and school performance variables including increases in tenth grade PSAT scores (RCT), GPA, gains in graduation rates $(60 \%$ increase in RJP schools compared to non-RJP schools), student and teacher reports of increased academic outcomes, and improvements in truancies and attendance. However, positive gains in these outcomes have not been consistently found and need additional study, which should be expected given that RJP is not an intervention that was designed for academic improvement directly, but more indirectly (increasing opportunities to learn by not being suspended and expelled).

Elementary schools. Restorative justice practices have been found to improve outcomes for all students across the K-12 spectrum. Research is emerging on the specific effectiveness of this approach in elementary (K-5) settings. When six schools implemented whole school restorative practices, it was shown that student behavior was impacted in the following "five key ways: harmony, empathy, awareness and accountability of one's own actions, respectful relationships, and thinking in a reflective way" (Kehoe, Bourke-Taylor \& Broderick, 2018). Furthermore, the Los Angeles Unified School District implemented a suspension ban that was later paired with restorative justice practices which showed a decrease in suspensions and a steeper decrease for those populations who have been disproportionately suspended at higher rates in the past (Hashim, Strunk \& Dhaliwal, 2018). Students that were referred for restorative interventions were found to be $35 \%$ less likely to get an out-of-school suspension, which is considered a punitive disciplinary measure (Gregory, Huang, Anyon \& Greer, 2018). Schools that have implemented an RJP to discipline see a decrease in repeat offending, lower number of suspensions, and fewer referrals related to bad behavior (Russell \& Crocker, 2016). There are higher levels of satisfaction found among participants of RJP, improved school environment, and increased student self-esteem (Russell \& Crocker, 2016). RJP has proven to be beneficial for all involved, even at the systemic level. 


\section{RJ Framework as a Means of Addressing Racial Inequalities}

One of the strengths of the RJ framework is that it addresses racial inequality and focuses on systemic racism (Song \& Swearer, 2016). In order to create better outcomes for marginalized students, we must directly address the racial bias that underlies disparate discipline practices, and recognize that practices built on the foundation of these biases negatively impact the lives of Black and Indigenous students of color. We cannot continue to ignore the existing racial inequalities seen in current, traditional discipline practices because when we do, we allow for implicit bias to continue creating discrepancies in treatment of students of color and results in unjust outcomes in all areas of student development. For example, implicit anti-Blackness results in Black children being disciplined harsher and more often than their White peers, even when Black students are not actively exhibiting any behavioral concerns (Sevon et al., 2021). RJ and its ability to promote racial equity and combat systemic racism in schools needs to be examined more closely due to its potential to enact change and address issues in regards to disportionality by use of traditional, exclusionary discipline practices (Song \& Swearer, 2016). Future research on RJP needs to place emphasis on anti-racism and advocacy as a means to promote social justice in schools (Song et al., 2020).

\section{Secrets to Success in Implementing RJP in Schools}

1. Multi-Tiered Systems of Support - RJP should be comprehensive focusing on prevention. This is best delivered as part of a multi-tiered system of supports (MTSS) that includes three tiers of support for students (see Figure below). Beginning with proactive and preventative strategies to support all students, MTSS builds more support for students as they need it. While there are various types of MTSS discussed, it is essential that it is responsive to the diverse cultural experiences of the student population, which is why RJP is highly recommended. Restorative justice practices as a model of MTSS focuses on creating a school culture of community, addressing harms, and restoring relationships that have been shown to be critical for students of color. In addition, RJP may address implicit bias in discipline decisions most effectively and highlights cultural responsiveness. RJP-MTSS may also integrate other strategies including Positive Behavior Intervention Supports (PBIS) which focuses on the behavioral support, Social Emotional Learning (SEL) focusing on skills in thinking, managing emotions, and friendships; and Trauma-sensitive (or informed) Schools that focuses on supporting students who may be experiencing symptoms related to chronic or acute trauma.

2. Critical RJP Ingredients - At the minimum, RJP implemented at the Tier 2 or 3 levels (i.e., after a rule violation has occurred), needs to include these two ingredients for it to be consistent with RJP best practices. First, students who violate school rules, those who are impacted by rule violations, and community members (e.g., administrator, facilitator, bystander) meet together to share how the violation harmed the relationships 
within the community and their needs. Second, they determine collaboratively how the students who caused the harm can take responsibility for it and make repairs (action plan).

3. School-wide Implementation - The most effective RJP are implemented universally throughout the school. These practices lose their power when they are implemented inconsistently or only with a select group of students. RJP practices help shape the culture of the school community and have been found, repeatedly, to foster a positive school climate. To successfully initiate universal RJP, all school personnel must be trained throughout the school. As a part of this training, school personnel should receive information on the benefits and challenges associated with implementation. Plans should be made to navigate anticipated challenges based on the unique school culture. The training should be consistent, refreshed periodically, and include ongoing monitoring and evaluation of the practices. Further, this monitoring should include measures of fidelity (are the practices being implemented as they should be), feasibility (can the practices reasonably be implemented as they should be), and effectiveness (are the practices working). Outcomes should be regularly shared with stakeholders such as teachers, parents, and students.

\section{Conclusion}

Restorative justice practices (RJP) have been shown to be effective across a range of important school outcomes including reduction of exclusionary discipline rates, growth in academics, school safety, and relationships within schools (teachers, students, families). RJP also has the potential to assist educators in becoming change agents in the social justice movement, by creating a safe environment that addresses issues with disportionality by use of traditional discipline practices. It is essential that RJP is implemented effectively and consistently in schools to improve school safety and increase high school graduation rates.

\section{References}

Augustine, C. H., Engberg, J., Grimm, G. E., Lee, E., Wang, E. L., Christianson, K. \& Joseph, A. A. (2018). Can Restorative Practices Improve School Climate and Curb Suspensions? Retrieved from https://doi.org/10.7249/RR2840

Gregory, A., Huang, F. L., Anyon, Y., Greer, E. \& Downing, B. (2018). An examination of restorative interventions and racial equity in out-of-school suspensions. School Psychology Review, 47(2), 167-182. 
Hashim, A. K., Strunk, K. O. \& Dhaliwal, T. K. (2018). Justice for all? Suspension bans and restorative justice programs in the Los Angeles Unified School District. Peabody Journal of Education, 93(2), 174-189.

High Hopes Campaign (2012). Restorative Justice in Chicago Public Schools. Chicago: High. Hopes Campaign.

Katic, B., Alba, L. A. \& Johnson, A. H. (2020). A Systematic Evaluation of Restorative Justice Practices: School Violence Prevention and Response. Journal of School Violence, 19(4), 579-593. Retrieved from https://doi.org/10.1080/15388220.2020.1783670

Kehoe, M., Bourke-Taylor, H. \& Broderick, D. (2018). Developing student social skills using restorative practices: a new framework called HEART. Social Psychology of Education, 21(1), 189-207.

Leary, M. R., Kowalski, R. M., Smith, L. \& Phillips, S. (2003). Teasing, rejection, and violence: Case studies of the school shootings. Aggressive Behavior: Official Journal of the International Society for Research on Aggression, 29(3), 202-214.

Lewis, S. (Ed.). (2009). Improving School Climate: Findings from Schools Implementing Restorative Practices. PA: International Institute for Restorative Practices.

Mansfield, K. C., Fowler, B. \& Rainbolt, S. (2018). The Potential of Restorative Practices to Ameliorate Discipline Gaps: The Story of One High School's Leadership Team. Educational Administration Quarterly, 54(2), 303-323.

McCluskey, G., Lloyd, G., Stead, J., Kane, J., Riddell, S. \& Weedon, E. (2008). 'I was dead restorative today': From restorative justice to restorative approaches in school. Cambridge journal of education, 38(2), 199-216.

Russell, S. \& Crocker, D. (2016). The institutionalisation of restorative justice in schools: a critical sensemaking account. Restorative Justice, 4(2), 195-213.

Sevon, M., Levi-Nielsen, S. \& Tobin, R. (2021), Addressing Racism and Implicit Bias-Part 1: A Response to the Framework for Effective Discipline. Communiqué, 49(5), 10-12.

Song, S. Y., Eddy, J. M., Thompson, H. M., Adams, B. \& Beskow, J. (2020). Restorative Consultation in Schools: A Systematic Review and Call for Restorative Justice Science to Promote Anti-Racism and Social Justice. Journal of Educational and Psychological Consultation, 30(4), 462-476. 
Song, S. Y. \& Swearer, S. M. (2016). The Cart Before the Horse: The Challenge and Promise of Restorative Justice Consultation in Schools. Journal of Educational and Psychological Consultation, 26(4), 313-324.

Sumner, M. D., Silverman, C. J. \& Frampton, M. L. (2010). School-based restorative justice as an alternative to zero-tolerance policies: Lessons from West Oakland. Thelton E. Henderson Center for Social Justice.

Weber, C. \& Vereenooghe, L. (2020). Reducing conflicts in school environments using restorative practices: A systematic review. International Journal of Educational Research Open, 1, 100009. Retrieved from https://doi.org/10.1016/j.ijedro.2020.100009

Wong, D. S., Cheng, C. H., Ngan, R. M. \& Ma, S. K. (2011). Program effectiveness of a restorative whole-school approach for tackling school bullying in Hong Kong. International journal of offender therapy and comparative criminology, 55(6), 846-862.

Yatsko, S. (2014, April 30). Common school performance frameworks. Retrieved February 21, 2021. Retrieved from https://www.crpe.org/research/districtchartercollaboration/ commonschoolperformance

\section{Authors}

Samuel Y. Song

Counselor Education, School Psychology, and Human Services University of Nevada, Las Vegas

4505 S. Maryland Pkwy., Las Vegas, NV 89154, United States

sam.song@unlv.edu

Taylor L. Milner

Counselor Education, School Psychology, and Human Services University of Nevada, Las Vegas

4505 S. Maryland Pkwy., Las Vegas, NV 89154, United States

milnet1@unlv.nevada.edu

Heather Thompson

Counselor Education, School Psychology, and Human Services University of Nevada, Las Vegas 4505 S. Maryland Pkwy., Las Vegas, NV 89154, United States heather.thompson@unlv.edu 
Tara Raines, Ph.D.

Morgridge College of Education

University of Denver

1999 E. Evans Ave.

Denver, CO 80208

Tara.Raines@du.edu

Alexis Sliva

Morgridge College of Education

University of Denver

1999 E. Evans Ave.

Denver, CO 80208

Alexis.Sliva@du.edu 